\title{
QUEEN'S
UNIVERSITY
BELFAST
}

\section{Study of reliability of fibre Bragg grating fibre optic strain sensors for field-test applications}

Surre, F., Sun, T., Grattan, K. T. V., Scott, R. H., Banerji, P., \& Basheer, P. A. M. (2012). Study of reliability of fibre Bragg grating fibre optic strain sensors for field-test applications. Sensors and Actuators A: Physical, 185, 8-16. https://doi.org/10.1016/j.sna.2012.06.026

\section{Published in:}

Sensors and Actuators A: Physical

\section{Document Version:}

Peer reviewed version

\section{Queen's University Belfast - Research Portal:}

Link to publication record in Queen's University Belfast Research Portal

\section{Publisher rights}

This is the author's version of a work that was accepted for publication in Sensors and Actuators A. Changes resulting from the publishing process, such as peer review, editing, corrections, structural formatting, and other quality control mechanisms may not be reflected in this document. Changes may have been made to this work since it was submitted for publication. A definitive version was subsequently published in Sensors and Actuators A, VOL 185, 10/2012

\section{General rights}

Copyright for the publications made accessible via the Queen's University Belfast Research Portal is retained by the author(s) and / or other copyright owners and it is a condition of accessing these publications that users recognise and abide by the legal requirements associated with these rights.

Take down policy

The Research Portal is Queen's institutional repository that provides access to Queen's research output. Every effort has been made to ensure that content in the Research Portal does not infringe any person's rights, or applicable UK laws. If you discover content in the Research Portal that you believe breaches copyright or violates any law, please contact openaccess@qub.ac.uk. 


\section{Accepted Manuscript}

Title: Study of Reliability of Fibre Bragg Grating Fibre Optic Strain Sensors for Field-Test applications

Author: Frederic Surre Richard H. Scott Pradipta Banerji

P.A.M. Basheer Tong Sun Kenneth T.V. Grattan

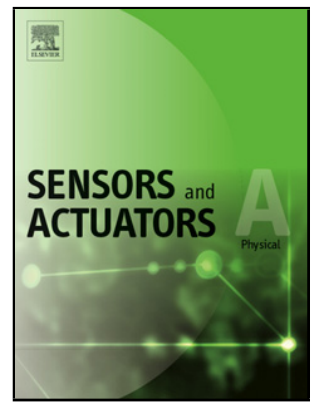

PII:

S0924-4247(12)00415-3

DOI: doi:10.1016/j.sna.2012.06.026

Reference: SNA 7917

To appear in: Sensors and Actuators A

Received date: 20-9-2011

Revised date: $22-6-2012$

Accepted date: 25-6-2012

Please cite this article as: F. Surre, R.H. Scott, P. Banerji, P.A.M. Basheer, T. Sun, K.T.V. Grattan, Study of Reliability of Fibre Bragg Grating Fibre Optic Strain Sensors for Field-Test applications, Sensors and Actuators: A Physical (2010), doi:10.1016/j.sna.2012.06.026

This is a PDF file of an unedited manuscript that has been accepted for publication. As a service to our customers we are providing this early version of the manuscript. The manuscript will undergo copyediting, typesetting, and review of the resulting proof before it is published in its final form. Please note that during the production process errors may be discovered which could affect the content, and all legal disclaimers that apply to the journal pertain. 


\title{
Study of Reliability of Fibre Bragg Grating Fibre Optic Strain Sensors for Field-Test applications
}

\author{
Frederic Surre ${ }^{1 *}$, Richard H. Scott ${ }^{2}$, Pradipta Banerji ${ }^{3}$, P.A.M. Basheer ${ }^{4}$, Tong Sun $^{1}$, \\ Kenneth T.V. Grattan ${ }^{1}$, \\ ${ }^{1}$ School of Engineering and Mathematical Sciences, City University London, London, EC1V 0HB, UK. \\ ${ }^{2}$ School of Engineering and Computing Sciences, Durham University, Durham, DH1 3LE, UK \\ 3 Department of Civil Engineering, Indian Institute of Technology Bombay, Powai, Mumbai 400076 , India \\ ${ }^{4}$ School of Planning, Architecture and Civil Engineering, Queen's University Belfast, Belfast BT7 1NN, UK \\ *Corresponding author - SEMS, City University London, Northampton Square, London, EC1V 0HB, \\ UK, Ph: +44 (0)2070403641, Fax: +44 (0)2070408568, e-mail: Frederic.surre.1@ city.ac.uk
}

\begin{abstract}
In this paper, the reliability and thus the suitability of optical fibre strain sensors for surface strain measurement in concrete structures was investigated. Two different configurations of optical strain sensors were used each having different mountings making them suitable for different uses in various structures. Due to the very limited time available to install the sensors and take result, commercially packaged sensors were used. In the tests carried out each sensor was mounted onto a concrete beam which was then subjected to a range of known and calibrated loadings. The performance of the optical strain sensors thus evaluated was compared with the results of conventional techniques. This comparison allows for selecting the best performing combination of sensor/mounting, i.e. long-gauge sensor with mounts bolted to threaded rods glued into the concrete for use in future work in a field test where a limited time window was available for installation, testing and post-test demounting.
\end{abstract}

Keyword: Fiber Optical Sensor, Strain Sensor, Fiber Bragg grating

\section{INTRODUCTION}

The use of Fiber Optic Sensors (FOSs) has represented a major opportunity for structural health monitoring, especially of civil engineering structures and in particular bridges. Their relatively small size, ease of use and potential to be multiplexed over the long lengths that represent many bridges make wider tests of their suitability for specific applications very important. Over the last 15 years, research groups around the world have instrumented various types of bridges - steel [1], concrete [2] and composite [3] - with various degrees of success. Thus these studies have demonstrated the potential for FOS to give civil engineers access to a wide range of useful information - for example to monitor strain in real time and on the impact of cracking and thus to assess better the health of the structure.

The prime focus has been on strain measurement, which is, for civil engineers, a key parameter of interest. Various optical techniques have been developed for this purpose where the most common are based on Fabry-Perot cavity-based sensors, Fiber Bragg gratings (FBG) or Brillouin scattering [4]. The majority of the attention has been devoted to the use of FBGs due to the unique properties among FOS to encode the information in the wavelength domain, which is less noise-sensitive, despite fully distributed measurements not being possible and the constraint on the wavelength spacing of the gratings themselves. In practical applications, these constraints can be overcome.

Considerable work has been done in this area by the authors using conventional techniques [5]-[6] and optical fiber sensors [7]. However often monitoring is performed by groups of engineers where expertise is not sufficiently shared between the sensor developers and the sensor users and so the opportunities for innovation in the design and application of the sensors are not taken - a problem that is addressed in the work herein. 
FOS sensors for strain measurement have been discussed in the literature and are available from commercial sources in a range of gauge lengths and with a variety of mountings. Both gauge length and mounting are important parameters when used on concrete structures primarily due to the inhomogeneous nature of concrete itself. A poor choice of sensor may lead to an error in the measurement and thus an inappropriate assessment of the soundness of the bridge. Sensors of the type described can be embedded in the structure or mounted on the surface where the latter case is more readily suited to retrofitting and thus is key to the concrete structure assessment in the present work. Embedded sensors are more suitable for new constructions as they can be readily installed during the building phase of a structure. However, most of the concrete infrastructure in developed countries has been built in the last fifty years; therefore effective surface mounting must be made a practical possibility for the installation of sensors in situations of the type to be described in this work.

In order to measure the actual strain experienced by a bridge, several important factors have to be carefully considered. The first is how to attach the sensor to the surface as the quality of the measurement depends on optimizing the degree of strain transfer from the structure to the sensors. The second is the gauge length of the sensor - e.g. the sensor gauge length is too short, the measurement made can be influenced by local surface strain and thus not be fully representative. On the other hand, if the gauge length is too long, different thermal effects on both ends of the sensor may alter the measurements. Finally, ensuring that the system is able to monitor up to the maximum desired or achieved strain level that is experienced is also important.

Strain transfer from a structure to an embedded optical fibre sensor has been studied both numerically and experimentally [8]-[9]. However, few systematic investigations involving comparative studies have been done on strain transfer for surface mounting of optical fiber sensors. One of the earliest reported [10] focuses on the strain transfer in the case of a bare fiber surrounded by a host material and a similar attachment method of the fiber to FRP laminates has been considered in [11]. Zhou et al [12] and Lin et al [13] have looked at the strain transfer for different packaged sensors bonded to an aluminium specimen. In work by Grabovac et al [14], the authors present an experimental study of different techniques for the attachment of a bare fiber in order to deploy a FOS network to monitor a large scale structure.

This paper presents the experimental evaluation of several different packaged FBG-based sensors in laboratory tests undertaken in advance of field tests. In light of the very short time 'window' when a major arterial route bridge (on which cracks had been observed) could be closed and sensors installed and measurements made commercially packaged sensors were used to ensure the reliability of the mounting of the sensors. Thus the aim was to select an appropriate and optimally performing sensor which could be installed rapidly and used immediately on the selected concrete bridge. To do so, it was decided that bare fiber sensors were not appropriate: it would be difficult to prepare all the surfaces properly and consistently and fix the sensors using adhesive in the time available for the tests. Thus it was decided to evaluate the possibility of the use of two different commercially packaged sensors of different gauge lengths and hence, evaluate several different mounting techniques for different (but known) loading levels of a concrete test beam in the laboratory which would be representative of the surfaces and conditions in the actual bridge. The outputs from the different FOS mounts used were compared with those from conventional electrical resistance strain gauges and demountable mechanical strain gauges. Thus in the second section of this paper, the different strain sensors used in this work are introduced and their main characteristics are measured. 
The third part of the paper is dedicated to discussing and evaluating the test set-up. Finally, in the last section the experimental results are revealed and thus conclusions on the suitability of each type of sensor and mounting techniques are drawn for application subsequently on the target bridge.

\section{STRAIN SENSORS}

\subsection{Fiber Bragg Grating Strain Sensors}

Before detailing the optical strain sensors used in this work, a brief review of the operation of Fiber Bragg Gratings (FBG) is provided. An in-fiber FBG is a periodic modulation of the refractive index of the core of a photosensitive fiber where the modulation of the refractive index is induced by UV light from a laser source and different techniques exist to fabricate FBG [15]. The periodic modulation acts as a filter reflecting one wavelength, the Bragg wavelength, which is expressed by the following formula [15]:

$$
\lambda_{B}=2 n_{e} \Lambda
$$

where $n_{e}$ is the effective refractive index and $\Lambda$ is the period of the grating.

A variation of the period of the grating or the effective refractive index (caused in this case by strain (and temperature) change) induces a shift of the Bragg wavelength. It is known that temperature variations induce a change of refractive index and grating period, while longitudinal strain mainly induces a change in $\Lambda$. The temperature or strain induced wavelength shift can be modeled by the following equation:

$$
\Delta \lambda=S_{\text {strain }} \Delta \varepsilon+S_{T} \Delta T
$$

where $S_{\text {strain }}$ and $S_{\mathrm{T}}$ are the strain and temperature sensitivities, respectively. $\Delta \varepsilon$ and $\Delta T$ are the strain and temperature variations respectively.

Eq. (2) highlights the temperature dependence of strain measurement, which is a well researched problem for FBG based strain sensors. In order to have a meaningful determination of the actual strain, it is necessary to have an accurate value of the temperature in the vicinity of the FBG. An overview of techniques researched for temperature compensation of FBG strain sensors can be found in the literature e.g. the work of Majumder et al [16].

Thus in this work, to prepare for the field tests which would follow, five commercially available fiber optic strain sensors were mounted on a specially fabricated reinforced concrete beam. All the packaged sensors have been fabricated by and purchased from MicronOptics ${ }^{\mathrm{TM}}$. Two different types of fiber optic sensors are used specified by the manufacturer as optical strain gauges and optical strain sensors. Their geometrical and optical characteristics are summarized in Table I.

Different mounting techniques are used to evaluate the strain transfer capability and the sensors' robustness under both light and heavy loading and thus to evaluate their practicality for field installation. Thus several points on the mounting can be made:

- Optical strain gauge with temperature compensation (os3600), termed OSG1, used mounts that each had a lug glued into a drilled hole (approximately $25 \mathrm{~mm}$ deep) in the concrete (as shown in Fig 1(a)); A second FBG is included in the same packaging. 
This FBG is only sensitive to temperature, therefore it can used to estimate the temperature and compensate the temperature dependence of the FBG measuring strain..

- Optical strain gauge with temperature compensation (os3600), termed OSG2, used mounts that were screwed into $25 \mathrm{~mm}$ deep fixings in the concrete (Fig 1(b)). After preliminary tests, these mounts were modified by replacing the screws and fixings with threaded rods glued using cyanoacrylate adhesive into the holes to which the mountings were firmly bolted. As for OSG1, a second FBG is included in the same packaging to perform temperature compensation.

- Optical strain sensor (os3120), termed OSA, glued onto the beam using cyanoacrylate adhesive (Fig 1(c)). No temperature compensation was provided;

- Optical strain sensor (os3120), termed OSB, was glued on the beam. The cyanoacrylate adhesive was applied to the sensor and left to set for 5 minutes before fixing the sensor onto the beam. No temperature compensation was provided;

- Optical strain sensor (os3120), termed OSC, glued to two large metallic plates using cyanoacrylate adhesive, which had previously been glued onto the beam using epoxy resin (Fig 1(d)). No temperature compensation was provided.

As described above, the five optical strain sensors are mounted differently. Gluing these sensors onto the beam requires physical pressure on the sensor until the glue cures. The time needed for this depends on the glue used and can vary from some minutes to tens of minutes. For Sensor OSA, ten minutes was necessary to guarantee a high level of strain transfer. Letting the glue applied onto the packaging of the sensor to partially set before fixing the sensor onto the beam could facilitate the installation of sensors during field work should this approach be chosen. Sensor OSB was mounted onto the beam using this approach.

Following preliminary tests with Sensors OSA and OSB, metallic plates have been glued to the beam before Sensor OSC was glued to this plate. Designed in order to increase the contact surface between the sensor and the beam, this technique makes Sensor OSC a compromise between average strain measurement (as can be expected with the optical strain gauges) and local strain as measured with the optical sensors. Furthermore, increasing the surface of contact should improve the robustness of the sensor and limit potential debonding.

For an out of laboratory (in the field) use of Sensors OSA, OSB and OSC, the lack of temperature compensation could be an issue due to the significant response of the wavelength change of the grating (the primary sensing mechanism) to temperature which could mask a small change in the strain. A solution where the temperature of the system is not sufficiently stable is that a temperature sensor in the vicinity of the three strain sensors could be used in order to remove any temperature effect on the FBGs and thus allow the actual strain to be evaluated. Fortunately, due to the controlled environment of the laboratory, such temperature compensation is not required for the tests presented in this paper. During these tests, the temperature both around and inside the beam was carefully monitored and a variation of less than half a degree has been measured - this could be construed at worst as an error in the strain measurement of a maximum of $\pm 3 \mu$ strain.

As can be seen from Table I, the (non-strained) Bragg wavelength for each sensor is separated by at least $5 \mathrm{~nm}$ and as the strain sensitivity of each sensor is between 1.2 and $1.4 \mathrm{pm} / \mu$ strain, five $\mathrm{nm}$ separation allows a maximum strain of $\pm 3500 \mu$ strain before any ambiguity is observed, which is more than sufficient for this work. Even during heavy loading, the strain 
measured is not expected to reach $1000 \mu$ strain and thus a five nanometer separation is sufficient to guarantee no overlap of the outputs of the FBGs used.

The monitoring of the wavelength changes from the five different FBG sensors is performed using a MicronOptics sm125 interrogator box allowing the recording of each Bragg wavelength, from which the strain values were obtained.

\subsection{Electrical Resistance Strain Gauges}

Electrical strain gauges were used so that comparative measurements from a non-optical source could be obtained and a strain gauged reinforcement bar was included in the test beam to provide detailed measurements of the longitudinal reinforcement strains. This bar was specially fabricated and had a diameter of $16 \mathrm{~mm}$ and contained 81 electrical resistance strain gauges (ersgs) spaced at $15 \mathrm{~mm}$ over the central $1200 \mathrm{~mm}$ length of the bar. The gauges were installed in a central longitudinal duct having a cross-section of $4 \times 4 \mathrm{~mm}$ (as shown in Fig. 2). Using bars of this type avoids degradation of the bond around the surface of the bar and thus permits monitoring of very detailed data pertaining to reinforcement strain and bond stress distributions to be obtained. Bars of this type have been used in a number of previous investigations and full details of their specialist manufacture by the authors can be found elsewhere [17]-[18]. The ersgs had a gauge length of $3 \mathrm{~mm}$ and an upper strain limit of $3 \%$. A three wire system was used for the gauge wiring and the data logger used provided double constant current energization to each gauge in turn.

\subsection{Demountable Mechanical Strain Gauge}

To provide a third independent measurement, surface strains on the concrete were measured using a demountable, mechanical strain gauge (a "Demec" gauge) in conjunction with a grillage of steel studs glued to the surface of the concrete. The studs were set at $200 \mathrm{~mm}$ at three levels over the central meter of the test beam, the level of most interest being that which coincided with the main tension reinforcement. It was known that this approach would only measure average strains over each $200 \mathrm{~mm}$ gauge length but this was deemed to be a useful independent back-up to the other measuring techniques being used.

\section{EXPERIMENTAL SET-UP}

Several key aspects of the components of the system evaluated in this work are described below.

\subsection{Concrete beam}

The reinforced concrete beam specially fabricated for this work as shown in Fig. 3 was 5200 $\mathrm{mm}$ long overall (4870 $\mathrm{mm}$ between simple supports), $250 \mathrm{~mm}$ deep and $300 \mathrm{~mm}$ wide. The main tension (bottom) reinforcement was provided from three $16 \mathrm{~mm}$ diameter high yield reinforcing bars (the centre one of which was the internally strain gauged bar) and the top reinforcement comprised two $12 \mathrm{~mm}$ diameter high yield bars. Cover to the centre of both the top and bottom reinforcements was $30 \mathrm{~mm}$. Links (stirrups) were provided in the beam between the supports and the load points to obviate the effects of any shear cracking but were omitted between the loads points as this was a shear-free zone in which providing links might actually lead to unwanted crack propagation.

\subsection{Loading system}

The beam was loaded in four point bending (Fig. 3) which provided a constant moment zone of $2500 \mathrm{~mm}$. Manually pumped hydraulic jacks were used and the loads applied were measured using load cells incorporated in the loading system. The various different fiber 
optic sensors, the Demec points and the ersgs were all positioned within the constant moment zone and at the same level in the beam (Fig. 4), thus permitting direct comparisons between all the various measurement techniques. A full set of readings was taken from all the sensors at each load stage during the tests.

\subsection{Test programme undertaken}

The experimental programme was developed by the civil engineering members of the team to be representative of what was to happen in the subsequent field tests and thus which would allow a full evaluation of the sensors. It comprised a series of (three) different load cycles associated with three different cracking regimes of the beam and therefore likely involving three different strain levels. The first corresponds to a light loading to induce micro-cracking while the second is an even lighter loading to remain in the non cracked zone. Finally the last loading is a heavy loading to a full cracking pattern of the beam as the beam could be 'tested to destruction' at this stage. The following gives more details on each loading.

- $\quad$ Test 1 - Loading to $5 \mathrm{kN}$ : Due to the nature of the beam used during these tests, a load of $5 \mathrm{kN}$ lead to the appearance of a number of micro-cracks. The beam was loaded incrementally to $5 \mathrm{kN}$ and then unloaded in a similar way, incrementally. The strain is recorded using Demec and ersgs at loads of $1.8 \mathrm{kN}, 3.5 \mathrm{kN}$ and $5 \mathrm{kN}$ (on the loading cycle) and $4 \mathrm{kN}, 2 \mathrm{kN}$ and 0 (on the unloading cycle) as can be seen from Fig 5a. Following this loading/unloading sequence, it was seen as possible to draw some preliminary conclusions on the reliability of the fiber optical strain sensors to measure low level of strain and to detect the appearance of micro-cracking

Test 2 - Loading to $4 \mathrm{kN}$ : The beam was then loaded directly to $4 \mathrm{kN}$ and then unloaded (as can be seen from the scheme outlined in Fig 5a). As $4 \mathrm{kN}$ is below the micro-cracking threshold of the beam, therefore no change in the strain should appear, compared to measurement sequence undertaken for a load of $4 \mathrm{kN}$ during load cycle 1 . The outcome of this test gives an indication of the repeatability of the measurement.

Test 3 - Loading to $20 \mathrm{kN}$ : The beam is loaded incrementally to a much higher level of load, to $20 \mathrm{kN}$ (and then unloaded incrementally). The strain was recorded using ersgs at loads of $5 \mathrm{kN}, 10 \mathrm{kN}, 15 \mathrm{kN}$ and $20 \mathrm{kN}$ (loading) and $15 \mathrm{kN}, 10 \mathrm{kN}, 5 \mathrm{kN}$ and 0 (unloading) as shown in Fig 5b. Such a load causes a full pattern of flexural cracks to be developed and, at $20 \mathrm{kN}$, the reinforcement was close to the onset of yield. This load cycle investigates the performance of the sensors on a cracked section and thus provides a good indicator of their robustness, and especially focusing on one of the key parameters of this test, the quality of each mounting technique used.

Unlike Demec and ersgs, the fiber optic strain sensors are continuously monitored, thus giving a value of the strain at each load as the measurement system allows for this.

\section{EXPERIMENTAL RESULTS AND ANALYSIS}

\subsection{Test 1 and Test 2}

Fig. 6 summarizes the variation of the strains recorded for the five sensors indicated, as a function of time. A comparison of these results with the loading variations shows that all the sensors are able to capture the strain induced by the load, or at least a significant fraction of the induced strain as explained below. 
It is clear from Fig. 6 that sensors OSA and OSB are detecting lower strain than is seen at the three other optical sensors. The highest value of strain is picked up by OSC. The difference in values between sensors OSA, OSB and OSC may be explained by the small difference in the surfaces of the beam and thus of the contact of the sensors with different parts of the beam itself. OSA and OSB have similar surfaces but slightly different types of bonding are used however and the measured values are comparable. Due to the use of the metallic plates (see Fig. 1), sensor OSC is mounted with an enhanced contact surface with the beam and its output thus should be more sensitive to strain changes. The optical strain gauges gave values in the same region where the differences in the measured strain are likely due to the position of the sensors and the differences in the local strain experienced there. In Section 4.3 below, these results are compared with those from the ersgs ${ }^{1}$ in the rebar in order to reach conclusions regarding the optimum performance of the optical sensors.

After unloading the beam, all sensors presented residual strain. As sensors OSA and OSB had been installed during a previous test two months earlier, it can be considered that they are 'settled' (in terms of their installation) and therefore the residual strain is due to a modification of the beam itself. It has been previously established [19] that a $5 \mathrm{kN}$ load is sufficient to induce micro-cracking in the beam. Since these cracks do not fully close on unloading residual strains are developed in both the concrete and the reinforcement, exacerbated by some creep in the concrete.

During the second test (Test 2), the beam is loaded to $4 \mathrm{kN}$. The strain measured by the five optical sensors can be seen from Fig. 6, shown over the time period 69 to 76 minutes. These results show that for the two optical strain gauges, OSA and OSB, the strain measured is comparable to the strain measured when the beam was unloaded to $4 \mathrm{kN}$. However, for OSC the reloading induced a marginally lower amount of strain, with the difference being lower by $5 \mu \varepsilon$. This is not a significant change and could have a number of causes, including measurement noise or a small variation of the condition of the beam around this sensor. However, the results are consistent with expectation, taking into account that a load of $4 \mathrm{kN}$ does not induce further micro-cracking of the beam, i.e. after removing the load, the strain distribution along the beam is identical to the original distribution prior to the $4 \mathrm{kN}$ loading.

During Tests 1 and 2, the five optical sensors behaved consistently and in a way expected from the specification. They have shown that they are able to detect the cracking that appears when the beam is loaded to $5 \mathrm{kN}$ and the reloading of the beam shows that the five sensors give a repeatable reading. Thus for use up to loading of $5 \mathrm{kN}$, the use of such sensors does not present any major challenges in tests of this type, besides recognizing the source of the small differences in the readings obtained from the following pairs of sensors: OSA/OSB, OSG1/OSG2 and additionally from OSC. Further comment is made on this issue in Section 4.3.

\subsection{Loading up to $20 \mathrm{kN}$}

The conditions for the test and the set-up used are identical to Tests 1 and 2, with the maximum load being increased as indicated. Results were recorded and Figs. 7(a) and (b) respectively show the variation of strain measured by the optical strain gauges and optical strain sensors respectively. Figure 7a demonstrates that the two optical strain gauges are able to measure strain levels induced by a load of up to $20 \mathrm{kN}$. However, as the test progresses, when the load is increased above $10 \mathrm{kN}$, the two sensors show different readings and OSG2

\footnotetext{
${ }^{1}$ Due to the length of the optical strain gauges, the Demec cannot be used to compare the value of strain.
} 
outputs a higher strain than OSG1. These sensors are located on opposite extremes of the constant strain zone (Fig. 4); and thus they would be expected to measure comparable strain as the loading is symmetrical. As the strain is identical on both sides of the constant moment zone of the beam, the cause of this difference in the reading is attributed to the mounting of the two OSGs and it would appear that one of the mounting techniques is not able to transfer the strain at the high loading level. The comparison with the output from the ersgs (as discussed in Section 4.3) provides further information on which mounting is more suitable for high load measurement.

For such higher levels of load, the beam becomes cracked and a full-cracking pattern can be seen of Fig. 4. The effect of cracking on the strain is clearly picked up by the two optical strain gauges. Figure 7(a) shows the strain measured when the load is progressively removed and as expected, the descending loading steps correspond to those for the ascending level of loading. However, the strain measured is very different than the strain measured when the load is increased. When the beam has been unloaded, the strain difference for OSG2 is around $280 \mu \varepsilon$ which is consistent with the elasticity of the concrete being reduced by the heavy loading.

Unlike the situation for the OSG, the three devices, OSA, OSB and OSC cannot be relied upon to monitor the highest load, whatever the mounting technique used. As can be seen from Fig $7 \mathrm{~b}$, each of the three devices OSA, OSB and OSC failed under some of the applied loading conditions used. Both OSA and OSB failed when the load was larger than $5 \mathrm{kN}$, OSB failing slightly at a slightly lower value than OSA. OSC started failing when the load was raised above $10 \mathrm{kN}$. In terms of strain value, OSB fails at $90 \mu \varepsilon$, OSA at $100 \mu \varepsilon$ and OSC was able to measure up to $250 \mu \varepsilon$.

These results can be explained by recognizing the partial debonding of the optical strain sensors. When the load increases, the strain measured by the optical sensors also increases until the load is too large and the bonding of the sensor to the beam is not able to transfer the strain properly. This explanation is supported by the fact that OSB, which had been glued to the beam after the epoxy has been let to set for 5 minutes, was the first to fail. This technique, whilst easing the manual work required does not create a bond for the sensor which is as strong to the concrete. On the other hand, OSC, which has a larger area of contact, can sustain a larger load before debonding was experienced.

In summary of the above, during this test the optical strain gauges have been able to pick up the change of strain for a load up to $20 \mathrm{kN}$ without any signs of debonding. The strain measured by OSG2 when the load was removed also highlights the ability of this sensor to detect the effect of the beam cracking under the applied load. However, the three optical strain sensors OSA, OSB and OSC have failed for different levels of strain. Of these OSC, which has the larger surface contact area, was able to withstand a strain up to $250 \mu \varepsilon$ in the tests carried out. However, all optical strain sensors (OSA, OSB and OSC) were not able to follow the deloading cycle, which is strongly indicative of debonding.

\subsection{Sensor performance - comparison}

By comparing the performance of the optical strain sensors during the three tests, it is possible to draw preliminary conclusions on their suitability to measure strain under different load conditions and on the ability of different mounting techniques to transfer strain up to $20 \mathrm{kN}$. These are key features for the field tests planned to follow these laboratory investigations. However, as they output different levels of strain for the same applied load, a comparison of 
their performances with the outputs of the ersgs and, when possible, the Demec is valuable to allow the maximum information on which type of optical sensor and which bonding technique give the best result to be drawn. Figures 8 to 11 present the comparison of all the sensors for the different loading cycles. Figure 8 corresponds to Test 1 and Fig 9 to Test 2 . The ascending loading in Test 3 and the descending loading in Test 3 correspond to Figs 10 and 11 respectively.

From Fig 8, it is clear that, for any constant load, the strain measured by the electrical resistance strain gauges varies significantly along the beam. This is due to the post cracking loss of strain compatibility between the reinforcement and the concrete leading to strain gradients being developed in the former adjacent to crack positions. However, it is possible then to use an average ersgs reading to create an effective cross-comparison with the outputs of the five optical sensors. The measurements of strain from both OSG1 and OSG2 are in good agreement with that from the ersgs, taking into account that the optical strain gauges are measuring an average strain over their greater length - this shows that OSA and OSB are differing in their measurement of the strain by 20 to $30 \mu \varepsilon$. The result from OSC shows that by comparison to the outputs of the ergs, it is overestimating the measured strain by about 20 $\mu \varepsilon$. The optical strain sensors OSA, OSB and OSC, due to their compact size, are measuring local strain at the surface of beam, which can be influenced by many of the smaller scale parameters of the concrete. However, even for a light load, as in the test under consideration, a significant difference appears when compared to the strain monitored inside the reinforcement bar and this must be considered. Before any cracks develop, there is good strain compatibility between the steel and concrete but post cracking this is lost, hence the discrepancies between surface and rod strains at many locations along the beam. This is evident in 0 and lower strain values in fig 8 .

The Demec reading obtained again is not totally consistent with the outputs from either the ersgs or the optical sensors, as would be expected given the different measurement environment. In the vicinity of sensor OSC, the agreement between the Demec measurement and that from the ersgs is very good, while still being significantly different from that from the two other locations.

The conclusions that may be drawn from Fig 9 are comparable to those obtained from Test 1 (fig. 8). The outputs from the optical strain gauges are found to be in good agreement with those from the ersgs while OSA and OSB appeared to 'under-read' the strain, while the output from OSC would suggest the opposite and 'over-read' it. When the load was $4 \mathrm{kN}$, OSA (resp. OSB) measured a strain of $38 \mu \varepsilon$ (resp $40 \mu \varepsilon$ ), compared to an average strain of $69 \mu \varepsilon$ (resp $64 \mu \varepsilon$ ) for the ersgs. OSC measured a strain of $97 \mu \varepsilon$ instead of $74 \mu \varepsilon$ for the ersgs.Demec reading agrees with the ersgs for the vicinity of both OSB and OSC. It is interesting to note that when the Demec results are averaged over between $480 \mathrm{~mm}$ and 680 $\mathrm{mm}$, the agreement with the averaged strains from the strain gauged bar is remarkably good (71 $\mu \varepsilon$ compared with $74 \mu \varepsilon$ ). This correlation gave confidence in using the ersgs reading as effective comparison values to allow the outputs of the fiber optic sensors to be accurately assessed.

The result of Test 3 involving the heavy loading, is presented in Figs 10 and 11. Due to the large deformation of the beam and the large strain induced, the Demec readings were not reliable and the focus has been on both the outputs from the ersgs and the optical sensors. Before failing, the results from the OSC strain measurement agrees well with the ersgs readings ( $272 \mu \varepsilon$ measured by OSC compared to $287 \mu \varepsilon$ measured by the esrg), as can be seen 
in Fig 10. For a loading up to $10 \mathrm{kN}$, both OSG1 and OSG2 are in good agreement with the results from the ersgs. The readings from the esrgs located across OSG1 vary between 240 and $415 \mu \varepsilon$, when OSG1 reading is $306 \mu \varepsilon$. For OSG2, the esrg readings vary from 171 to 340 $\mu \varepsilon$, when OSG2 reading is $295 \mu \varepsilon$. For loading levels of between $10 \mathrm{kN}$ and $20 \mathrm{kN}$, the reading from OSG1 underestimates the strain compared to the measurement from the esrgs, while the output from OSG2 is still in good agreement (about 1\% difference between $911 \mu \varepsilon$ measured by OSG2 and an average $921 \mu \varepsilon$ measured by esrgs). Finally, when the load is removed (as shown in Fig 11), the sensor OSG1 underestimates the strain by up to $300 \mu \varepsilon$ compared to the ersgs. This anomalous result can be explained by the mounting technique not being able to withstand the high level of strain whilst the output from OSG2 maintains good agreement with the electrical strain gauges. The esrgs measured a residual strain of $343 \mu \varepsilon$ when OSG2 measured a strain of $303 \mu \varepsilon$.

From the comparison between the different sensors installed on the beam under different loading conditions, it can be concluded that the optical strain gauges (OSG1 and OSG2) show better performance compared to the optical strain sensors (OSA, OSB and OSC), with OSG2 being the most reliable installed sensor. Key differences arise from the fact that the OSG family, due to their longer gauge length, are measuring average strain, while the OSA,B,C family are measuring local strain. It has been demonstrated that it is possible to improve the performances of the OSA,B,C family by increasing the surface of the sensor in contact with the beam as OSC is able to measure strain up to $250 \mu \varepsilon$. The strain is slightly overestimated for light load but it is in acceptable agreement (less than $10 \%$ difference) with the ersgs for the heavier load.

For the optical strain sensors (OSA,B,C family), it is necessary to allow the epoxy to cure fully while the sensor is on the beam as demonstrated by the slightly degraded performances of OSB compared to OSA. However, the gauge length is the deciding criterion to improve the bounding of the OS sensor. For the optical strain gauges, there are critical mounting issues and mounts bolted to threaded rods glued into the concrete give a far better performance than any other sensors or mounting techniques.

\section{PRELIMINARY RESULTS ON VASAI CREEK BRIDGE}

Fieldwork was performed on Vasai Creek Bridge, a 28 span prestressed concrete posttensioned box girder railway bridge located just north of Mumbai in India. The bridge was constructed in the mid 1980's with all spans (length $28.5 \mathrm{~m}$ ) simply supported. The bridge actually consists of two parallel and adjacent lines of concrete boxes each of which support a single line of railway. Sensors were mounted inside the western (uptide) end span at the southern end of the bridge. The insert of Fig 12 shows the layout of the sensors at mid-span of the end box. Pairs of optical strain gages were positioned in the center of the soffit (underside of roof) and at the bottom of each web (side walls) of the box (Fig. 12). Sensors were placed in line to provide redundancy. An ersg of gauge length $120 \mathrm{~mm}$ was placed next to each OSG in order to have reliable comparison.

The OSGs were clamped to the surface using the grouted stud technique selected after the lab tests. The ersg's were bonded directly to the concrete after surface preparation.

The six OSGs used were connected to a MicronOptics sm130 interrogator box recording data at $200 \mathrm{~Hz}$ rate.

Fig 12 shows the strain measured by the six OSGs when a suburban train passed on the bridge. It can be noted that sensor F does not give consistent results and was ignored. The reasons can be due to damage to the sensor or a problem of fixing. Due to the redundancy, this is not a problem as sensor $G$ gives consistent measurements. The five OSGs exhibit a similar pattern: four peaks with the first peak being the strongest. This is due to the suburban 
train design. Each train is a multiple unit, which crosses the bridge at around $80-100 \mathrm{kmph}$. The largest peak is due to the dynamic effect of the first bogie providing additional excitation to the structure.

Finally, Fig 13 compares the strain measured for OSG-C and the ersg located in its vicinity. The OSGs were unaffected by noise from the overhead electrical power supply to the trains, from the signal circuits or from the interference generated by tractions motors. As a consequence, the data obtained required very little post-processing. This is in marked contrast to the ersg's which picked up considerable noise from all these sources. It can be seen that both sensors measure the same pattern of strain variations and that the ersg strain is slightly larger than the one measured by OSG (about $4 \mu \varepsilon$ ).

\section{CONCLUSION}

In this paper, a study of the reliability of different fiber optic sensing devices and different mounting techniques to measure strain in a concrete structure by surface mounting has been investigated in a full laboratory investigation. Two long-gauge optical fiber sensors and three short gauges sensors have been used. Using a series of load cycles in order to subject the concrete beam to different levels of strain combined with the use of established strain measurement techniques, electrical resistance strain gauges and Demec, the performance characteristics of each sensor/mounting technique combination has been critically evaluated. It is demonstrated from this work that the long-gauge optical fiber sensors measures more reliably the strain of the concrete. This result is valid for all level of strain recorded during these tests. Further, the work has shown that the most reliable mounting technique is to use mounts bolted to threaded rods glued into the concrete. The work has also shown that the system can be set up, used and evaluated in the sort of narrow time window available when commercial operations are involved.

The short-gauge optical strain sensor performance is limited by two factors: a limitation of strain transfer at high strain and the measurement of local surface strain. However, the paper demonstrates that it is possible to reduce both effects and to improve the performance of this type of sensor by increasing the surface of contact between the sensor package and the beam. Further work would be needed in order to optimize the size of the package to guarantee the best strain transfer and the highest robustness of the bounding.

The conclusion of the work that the longer gauge devices, mounted securely, give the best performance has meant their selection for a series of field tests on a bridge made available for a limited period by Indian Railways and preliminary results of that set of tests are presented in this paper. A more detailed study will be reported in due course in the literature.

\section{ACKNOWLEDGEMENTS}

The authors would like to thank the UKIERI initiative for the funding provided. The authors are grateful for the assistance with experimental work given by Dr R Mokhtar (City University London), Mr S. Srinivasan (Queen's University Belfast) and the technical staff at Durham University.

\section{REFERENCES}

[1] W.Lee, J.Lee, C.Henderson, H.F.Taylor, R.James, C.E.Lee, V.Swenson, R.A.Atkins, W.G.Gemeiner, "Railroad bridge instrumentation with fiber-optic sensors", Appl. Opt., 38 (1999), 1110-1114. 
[2] T.H.T.Chan, L.Yu, H.Y.Tam, Y.Q.Ni, S.Y.Liu, W.H.Chung, L.K.Cheng, "Fiber Bragg grating sensors for structural health monitoring of Tsing Ma bridge: Background and experimental observation", Engineering Structures, 28 (2006), 648-659.

[3] G. Kister, D. Winter, R.A. Badcock, Y.M. Gebremichael, W.J.O. Boyle, B.T. Meggitt, K.T.V. Grattan, G.F. Fernando, "Structural health monitoring of a composite bridge using Bragg grating sensors. Part 1: Evaluation of adhesives and protection systems for the optical sensors", Eng Struct, 29 (2007), 440-448.

[4] H.-N.Li, D.-S.Li, G.-B.Song, "Recent Applications of Fiber Optic Sensors to Health Monitoring in Civil Engineering", Eng. Struct., 26 (2004), 1647-1657.

[5] P.Banerji, S.A.Chikermane, "Structural Health Monitoring of a Steel Railway Bridge for Increased Axle Loads”, Struct. Eng. Internation., 21 (2011), 210-217.

[6] Y. Bai, P.A.M. Basheer, D.J. Cleland, A.E. Long, "State-of-the-art applications of the pull-off test in civil engineering”, Int. J. Struct. Monitoring, 1 (2009), 93-103.

[7] D.O.McPolin, P.A.M.Basheer, A.E.Long, X.Weiguo; T.Sun; K.T.V.Grattan, "Development and Longer Term In Situ Evaluation of Fiber-Optic Sensors for Monitoring of Structural Concrete", IEEE Sensors J., 9 (2009), 1535-1547.

[8] D.Li, H.Li, L.Ren, G.Song, “Strain transferring analysis of fiber Bragg grating sensors”, Opt Eng, 45 (2006), 024402.

[9] P. Biswas, S.Bandyopadhyay, K.Kesavan, S.Parivallal, B.Arun Sundaram, K.Ravisankar, K. Dasgupta, "Investigation on packages of fiber Bragg grating for use as embeddable strain sensor in concrete structure", Sensors and Actuators A, 157 (2010), 77-83.

[10] F.Ansari, Y. Libo, "Mechanics of Bond and Interface Shear Transfer in Optical Fibre Sensors", J. Eng. Mechanics, 124 (1998), 385-394.

[11] K.-T. Lau, L.Yuan, L.-M. Zhou, J.Wu, C.-H. Woo, "Strain monitoring in FRP laminates and concrete beams using FBG sensors”, Composite Struct., 51 (2001), 9-20.

[12] J.Zhou, Z.Zhou, D. Zhang, "Study on Strain Transfer Characteristics of Fiber Bragg Grating Sensors", Journal of Intelligent Material Systems and Structures, 21 (2010), 1117 1122 .

[13] Y.B.Lin, K.C.Chang, J.C.Chern, L.A.Wang, "Packaging Methods of Fiber-Bragg Grating Sensors in Civil Structure Applications”, IEEE Sensors J., 5 (2005), 419-423.

[14] I.Grabovac, T.Nuyens, C.Davis, "Packaging and Mounting of In-Fibre Bragg Grating Arrays for Structural Health Monitoring of Large Structures", Defence Science and Technology Organisation, DSTO-TR-2490, Oct 2010.

[15] K.T.V.Grattan, B.T.Meggitt (Eds), Optical Fibre Sensor Technology, Volume 2: Devices and Technology, Kluwer Academic Publishers, 2000. 
[16] M. Majumder, T. K. Gangopadhyay, A. K. Chakraborty, K. Dasgupta, D.K. Bhattacharyam, "Fibre Bragg gratings in structural health monitoring-Present status and applications", Sensors and Actuators A,147 (2008) 150-164

[17] R.H.Scott, A.W.Beeby, "Long term tension stiffening effects in concrete", Proceedings of the American Concrete Institute (Structural Journal), 102 (2005), 31-39.

[18] R.H.Scott, R.T.Whittle, "Moment redistribution effects in Beams", Magazine of Concrete Research, 57 (2005), 9-20.

[19] Kong K.L., Beeby A.W., Forth J.P. \& Scott R.H., “Cracking and Tension Zone Behaviour in RC Flexural Members", Proc. ICE (Structures and Buildings), 160 (2007), 165172. 


\section{Figure captions}

Figure 1. Type and mounting of the five optical fibre strain sensors: (a) OSG1 bolted in, (b) OSG2 screwed with screws glued inside the beam, (c) OSA glued onto the surface of the beam using epoxy glue (mounting of OSB is similar to OSA) and (d) OSC glued onto larger metallic plates.

Figure 2. Schematic of the machined bar with ersgs inside the central duct.

Figure 3. Schematic views of the concrete beam. (a) Side view with the location of the loading system indicated by arrows and the position of the ersg's highlighted in yellow. (b) the cross section with the machined bar highlighted in yellow.

Figure 4. Instrumented beam: the positions of the five fibre optical sensors and the DEMEC are highlighted. All the sensors are located in the constant moment zone of the beam.

Figure 5. Loading cycle for (a) tests 1 and 2 and (b) test 3.

Figure 6. Measured strain using the optical strain sensors for test 1 and test 2.

Figure 7. Measured strain using (a) the optical strain gauges and (b) the optical strain sensors for test 3.

Figure 8. Comparison between ersgs, optical sensors and DEMEC for test 1. Brown = 0kN; Green = $3.5 \mathrm{kN}$; Red $=5 \mathrm{kN}$; Blue $=0 \mathrm{kN}$ (unloading)

Figure 9. Comparison between ersgs, optical sensors and DEMEC for test 2 . Blue =0kN; Green $=4 \mathrm{kN}$; Red $=0 \mathrm{kN}$ (unloading)

Figure 10. Comparison between ersgs, optical sensors and DEMEC for the loading of test 3. Brown = 5kN; Green $=10 \mathrm{kN} ;$ Red $=15 \mathrm{kN} ;$ Blue $=20 \mathrm{kN}$ (unloading)

Figure 11. Comparison between ersgs, optical sensors and DEMEC for the unloading of test 3. Blue= $20 \mathrm{kN} ;$ Red $=15 \mathrm{kN} ;$ Green $=10 \mathrm{kN} ;$ Brown $=5 \mathrm{kN} ;$ Black $=0 \mathrm{kN}$

Figure 122. Example of strain measured by the six OSGs when a suburban train passed on the Vasai Creek Bridge. Insert: location of the six OSGs inside the end box.

Figure 133. Comparison of OSG-C and the ersg located in its vicinity. 


\section{Figure 1}

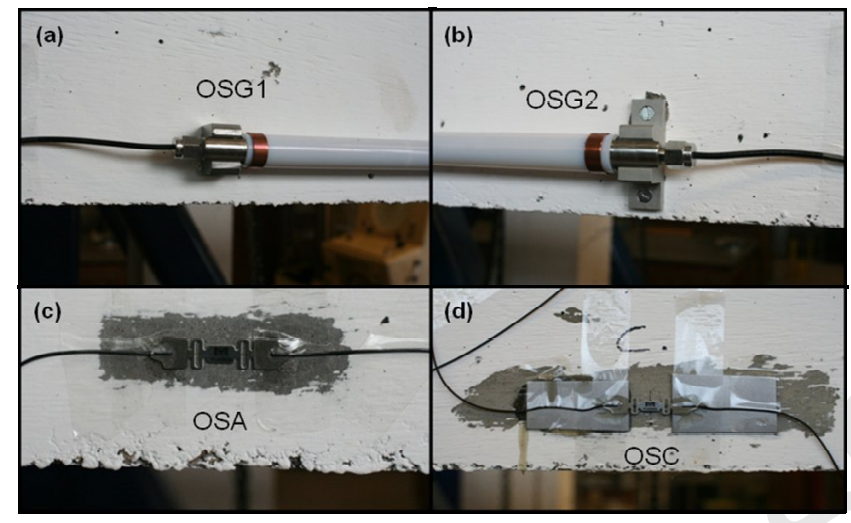

Page 15 of 30 


\section{Figure 2}

Machined bars

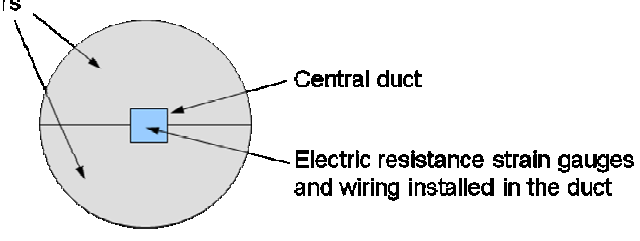


Figure 3

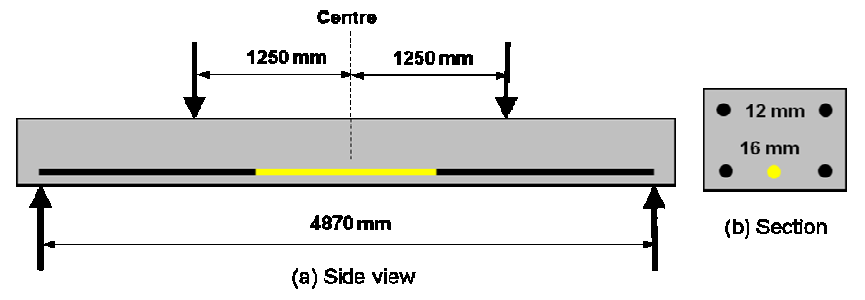




\section{Figure 4}

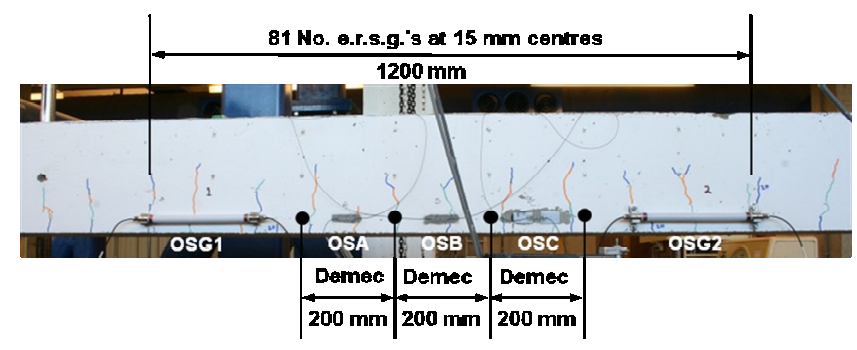


$\underline{\text { Figure } 5}$
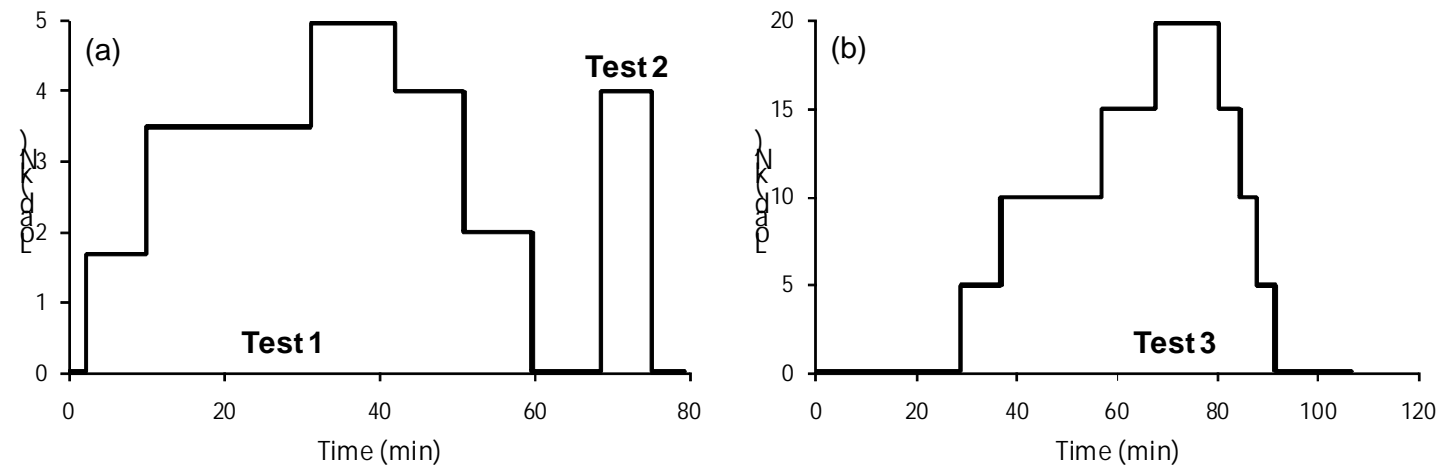
Figure 6

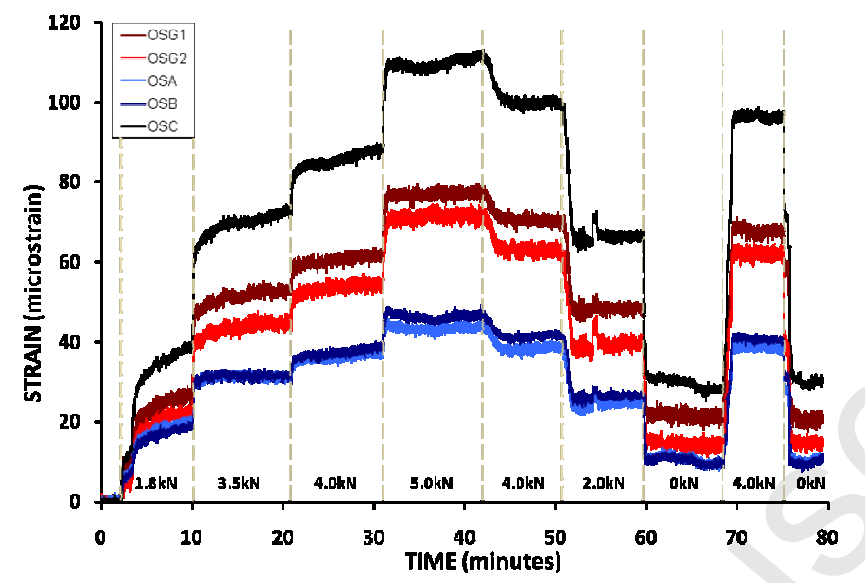




\section{Figure 7}
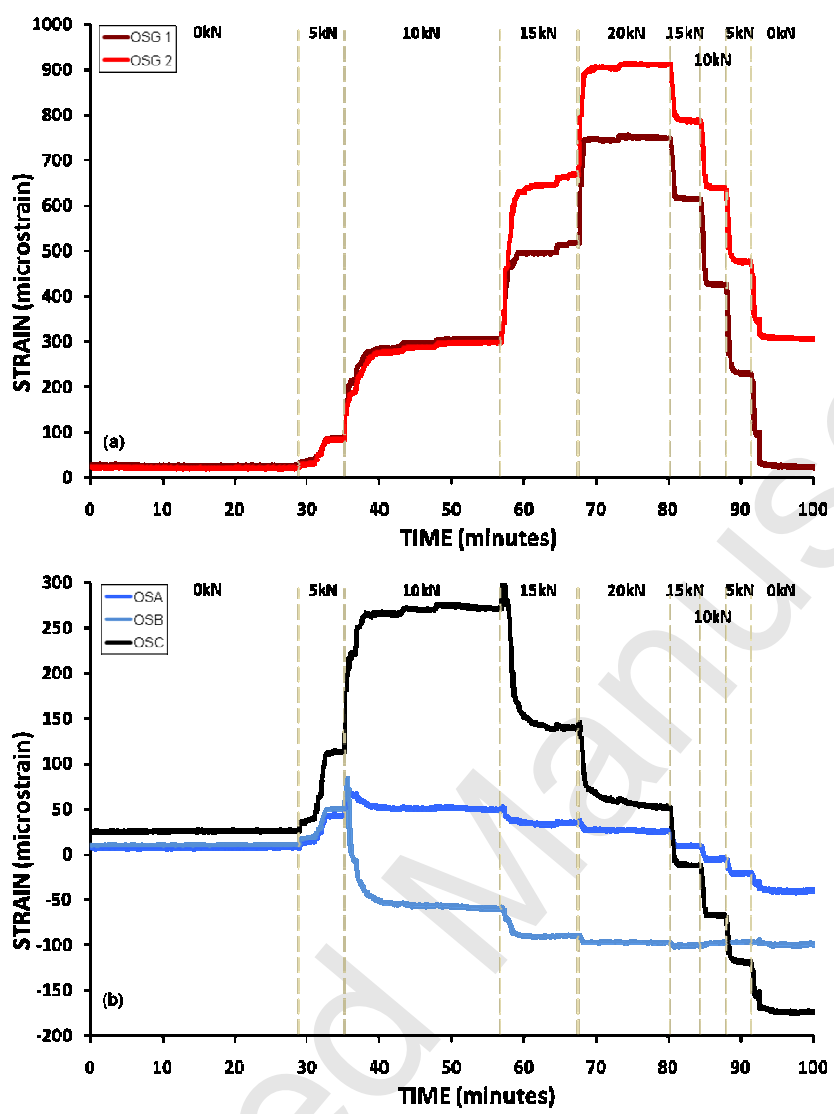


\section{Figure 8}

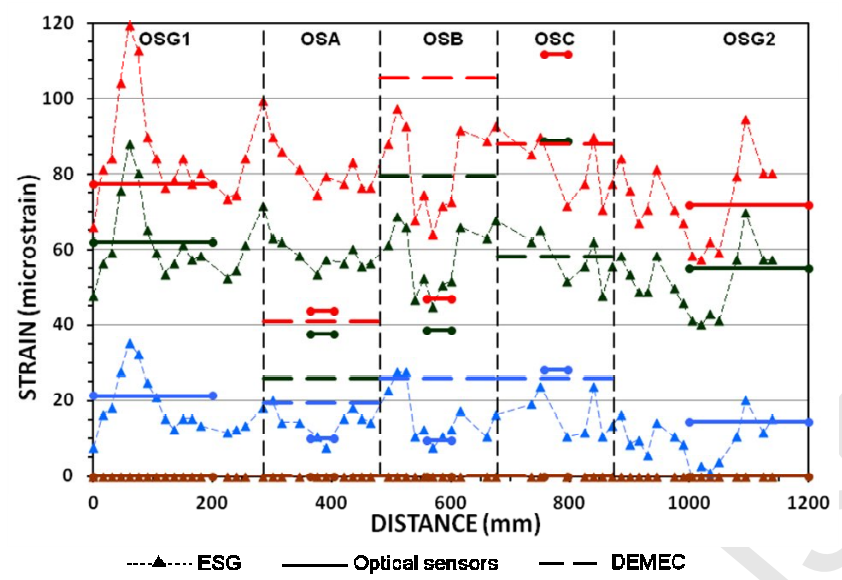


Figure 9

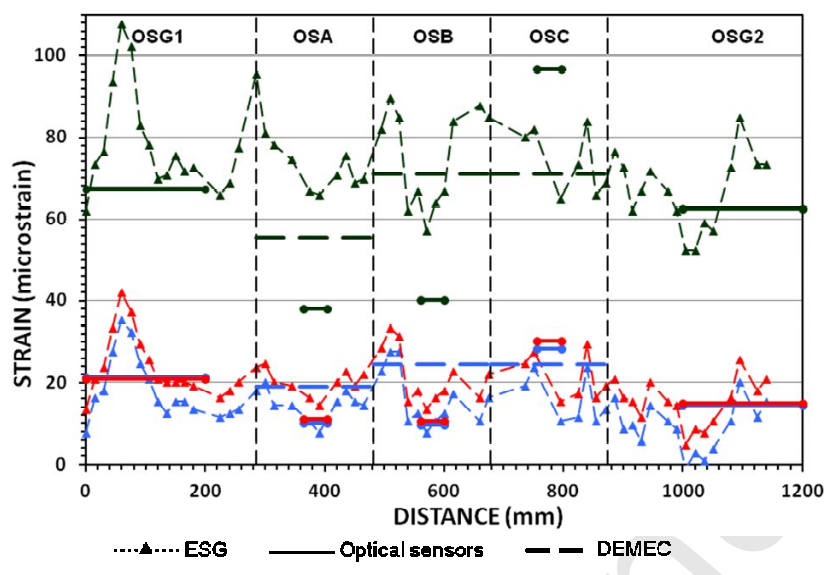




\section{Figure 10}

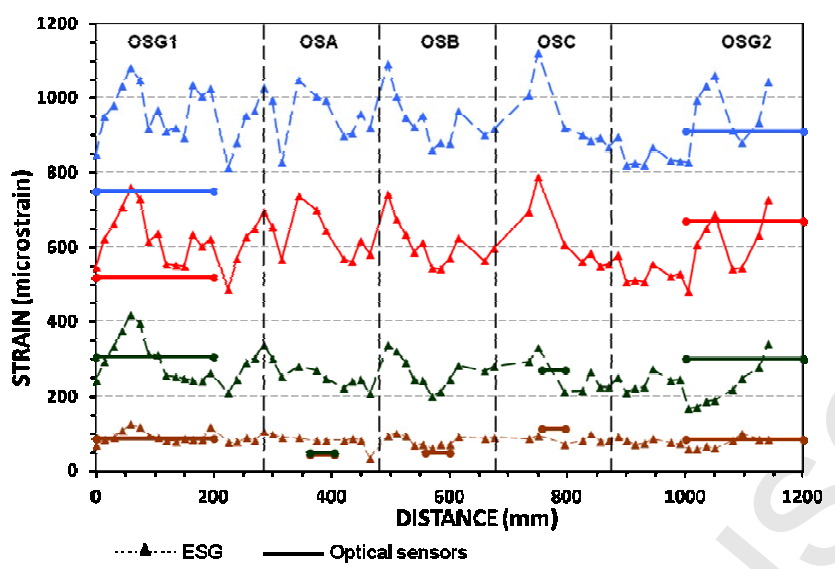




\section{Figure 11}

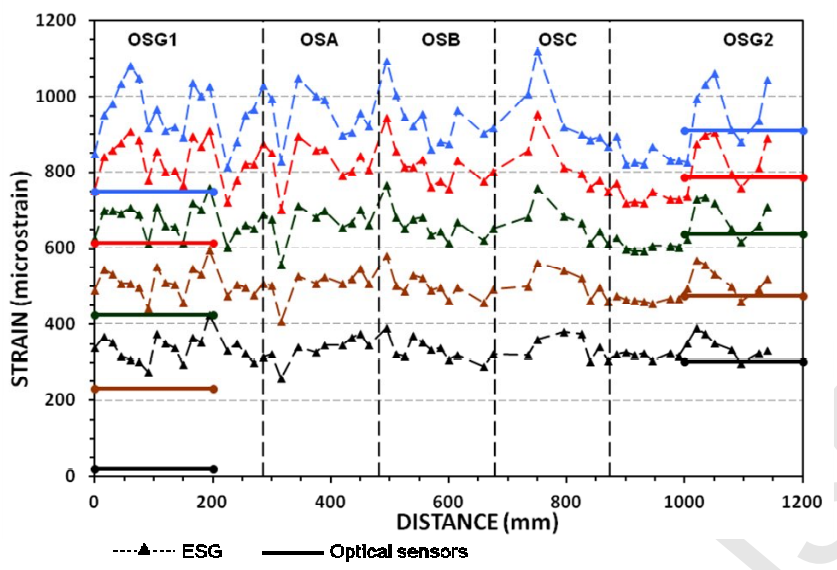


Figure 12

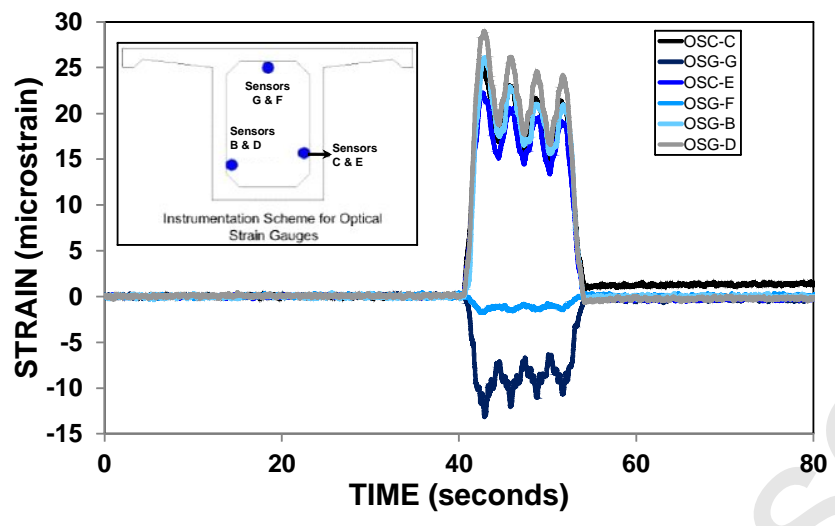




\section{Figure 13}

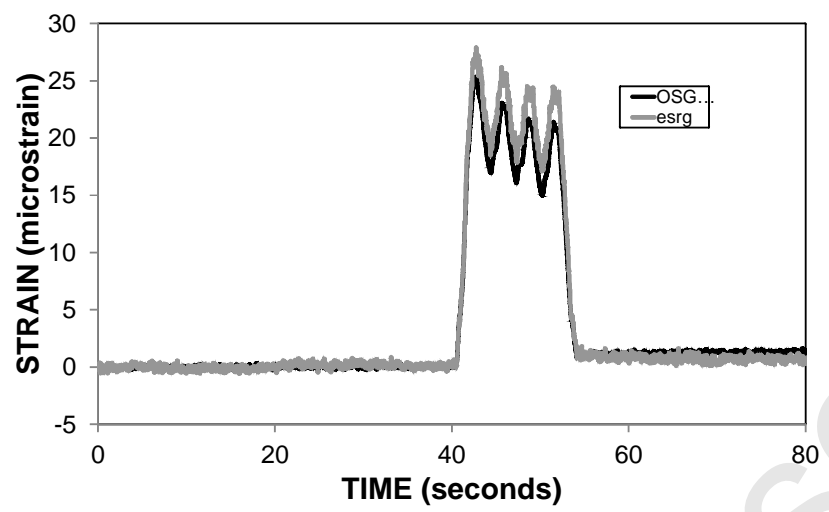


Table I. Characteristics of the fiber optic sensors (strain FBG).

\begin{tabular}{|c|c|c|c|c|c|}
\hline Name & OSG1 & OSG2 & OSA & OSB & OSC \\
\hline $\begin{array}{c}\text { Initial wavelength } \\
\text { @ } 22^{\circ} \mathrm{C}(\mathrm{nm})\end{array}$ & 1556.4 & 1546.3 & 1527 & 1535.2 & 1563 \\
\hline Gauge length (mm) & \multicolumn{2}{|c|}{250} & \multicolumn{3}{|c|}{22} \\
\hline $\begin{array}{c}\text { Temperature } \\
\text { sensitivity }\left(\mathrm{pm} /{ }^{\circ} \mathrm{C}\right)\end{array}$ & \multicolumn{2}{|c|}{10} & \multicolumn{3}{|c|}{8.3} \\
\hline $\begin{array}{l}\text { Strain sensitivity } \\
(\mathrm{pm} / \mu \varepsilon)\end{array}$ & \multicolumn{2}{|c|}{1.2} & & 1.4 & \\
\hline $\begin{array}{l}\text { Temperature } \\
\text { compensation }\end{array}$ & \multicolumn{2}{|c|}{$\mathrm{Y}$} & \multicolumn{3}{|c|}{$\mathrm{N}$} \\
\hline
\end{tabular}




\section{$\underline{\text { Bios }}$}

Frederic Surre received the BE, MSc and $\mathrm{PhD}$ in electronic engineering from INPT-ENSEEIHT, Toulouse, France in 1998, 1998 and 2003 respectively. In 1998, Frederic was a research engineer with ENSAE, France, where he was responsible for microwave photonics measurements. In 2004, he joined Trinity College's School of Physics, and Dublin City University's RINCE, Ireland. His research interests included photonic devices for all-optical communications and generation and guiding of terahertz waves. In 2008, he joined City University London to work on optical and terahertz sensors for structural health monitoring. He is chairman of the IEEE Instrumentation and Measurement Technical Committee on lasers and optical systems.

Richard H. Scott graduated from Queen Mary College (University of London). Then, Dr Scott worked for ten years in industry during which time he was involved with the design and construction of a wide range of civil engineering structures. During this period he also spent a year at Imperial College London studying for an MSc degree in Concrete Structures and Technology. Dr Scott joined Durham University in 1978 since which time he has undertaken research into the behaviour of reinforced concrete structural elements, a particular specialisation being the measurement of strain and bond stress distributions. He obtained his $\mathrm{PhD}$ degree in 1985 and is currently a member of several technical committees of the American Concrete Institute.

Pradipta Banerji graduated with a Bachelor's degree (B.Tech.) in Civil Engineering from Indian Institute of Technology Delhi in 1981, where he received the Director's Silver Medal for being the top-ranked student of his batch. He then obtained his Master's (M.S.) and Doctoral (Ph.D.) degrees from the Department of Civil Engineering at the University of California, Berkeley in 1982 and 1987, respectively. After spending almost 24 years as a faculty member, doing teaching and research, at Indian Institute of Technology Bombay, he has recently taken over as Director at the Indian Institute of Technology Roorkee. His current research interests are in the broad areas of Structural Health Monitoring and Earthquake Engineering.

P.A. Muhammed Basheer, Director of Centre for Built Environment Research, is a full professor at Queen's University Belfast, Northern Ireland, United Kingdom. He obtained BSc(Eng.) from University of Kerala in 1981, MSc(Eng.) from University of Calicut in 1986 and PhD from Queen's University Belfast in 1991. He is a Fellow of the Irish Academy of Engineering, Institution of Civil Engineers and American Concrete Institute. His current research interests include developing non-destructive tests and structural health monitoring systems for assessing the durability and performance of structures, sustainable constructions and high performance concretes. In these areas, he has authored more than 300 refereed technical papers.

Tong Sun was awarded the degrees of bachelor of engineering, master of engineering and doctor of engineering for work in mechanical engineering from the Department of Precision Instrumentation of Harbin Institute of Technology, Harbin, China in 1990, 1993 and 1998 respectively. She was awarded the degree of doctor of philosophy at City University in applied physics in 1999 and was an assistant professor at Nanyang Technological University in Singapore from year 2000 to 2001 before she re-joined City University in 2001 as a lecturer. Subsequently she was promoted to a senior lecturer in 2003, a Reader in 2006 and a professor in 2008 at City University, London. Prof. Sun has been leading a research team focused on developing a range of optical fibre sensors for a variety of industrial applications, including structural health monitoring, early fire detection, homeland security, process monitoring, food quality and automotive emission monitoring. She has been working closely with partners across disciplines from academia and industry, both in the UK and overseas. Prof. Sun is a member of the Institute of Physics and of the Institution of Engineering and Technology and a Chartered Physicist and a Chartered Engineer in the United Kingdom. She has authored or co-authored some 130 scientific and technical papers.

K.T.V. Grattan graduated in physics from Queen's University Belfast with a BSc (First Class Honours) in 1974 and $\mathrm{PhD}$ in laser physics. His research involved the use of laser-probe techniques for measurements on potential new laser systems. He has been active in fibre optic sensor research for nearly 30 years. Currently he is Dean of the Graduate School, City University London, London, UK. Prof. Grattan is a member of the Editorial Board of several major journals. He was awarded the Calendar Medal of the Institute of Measurement and Control in 1992, and the Honeywell Prize for work published in the Institute's journal. He is a Fellow of the Royal Academy of Engineering. He is the author and co-author of over seven hundred publications in major international journals and conferences and is the co-editor (with Professor B.T. Meggitt) of five volume topical series on optical fibre sensor technology. 


\section{Highlights}

- Long gauge length fiber optic sensors can measure higher strain

- Short-gauge length fiber optic sensors underead strain values

- Best fibre optic strain sensor attachment on concrete surface

- Validation of optical sensor system for field test application 